\title{
CONCEITOS, CATEGORIAS E ORGANIZAÇÃO DO CONHECIMENTO
}

\section{CONCEPTOS, CATEGORÍAS Y ORGANIZACIÓN DEL CONOCIMIENTO}

\author{
Nair Yumiko Kobashi - nykobash@usp.br \\ Professora Livre-docente Departamento de Biblioteconomia \\ Escola de Comunicações e Artes da Universidade de São Paulo \\ Marivalde Moacir Francelin - mfrancelyn@yahoo.com.br \\ Professor doutor Departamento de Biblioteconomia da Escola \\ de Comunicações e Artes da Universidade de São Paulo
}

\begin{abstract}
Resumo
$\mathrm{Na}$ contemporaneidade, o estatuto do conhecimento é analisado sob diversas configurações epistemológicas devido à emergência crescente de novas combinações interdisciplinares. Nesse contexto, a circulação e a apropriação social da informação assumem formas que exigem distintas maneiras de organizar informação e conhecimento. Para enfrentar esses desafios, diversos paradigmas sobre as relações entre conhecimento, conceito, categoria e sua operacionalização em linguagens documentárias coexistem na área da Organização da Informação e do Conhecimento. Os princípios tradicionais e canônicos da organização de conceitos e as novas teorias do conceito, reveladoras desses paradigmas, são apresentados, aqui, como resultado de um estudo exploratório. Ressalta-se, nas conclusões, a necessidade de aprofundar e confrontar esses paradigmas para que novas abordagens de organização da informação possam ser propostas.
\end{abstract}

\section{Palavras-chave}

Conceitos. Organização da informação. Organização do conhecimento. Teorias do conceito.

\section{INTRODUÇÃO}

No contexto atual, a produção e a circulação de informação e conhecimento em rede e nas redes, se expressam por metáforas que remetem às comunidades virtuais, comunidades em constante crescimento, construção e reconstrução. Castells (2008) e Lévy (1998) já chamaram a atenção para o fenômeno, salientando que as tecnologias em 
rede são os principais elementos que impactam a produção e o consumo de conhecimentos no mundo contemporâneo.

As mudanças acima assinaladas atualizam, igualmente, as abordagens sobre 0 estatuto do conhecimento. Assim, os paradigmas da complexidade, de Edgar Morin, e o papel do senso comum na ciência, de Boaventura Santos, estão de uma forma ou de outra, presentes nas construções teóricas, metodológicas e epistemológicas sobre o fazer científico, motivadas, em larga medida, pela emergência de novas combinações interdisciplinares que afloram a cada instante.

Nosso objetivo, no presente trabalho, é abordar algumas questões sobre a relação entre o conhecimento, os conceitos e as categorias neste cenário de crescente complexidade. Aprofundar tal relação é fundamental para a área da Organização da Informação e do Conhecimento (OIC), já que os conceitos e categorias, no contexto da OIC são submetidos a diferentes operações para viabilizar a circulação e apropriação social da informação e do conhecimento. A proposição de teorias e métodos de elaboração de linguagens de organização da informação (tesauros, taxonomias, ontologias) são os aspectos mais evidentes dessas operações. (FRANCELIN, 2010).

Daremos início à discussão apresentando os princípios tradicionais de organização de conceitos, que chamaremos de "canônicos". Esses princípios, baseados na Filosofia e na Lógica clássicas, têm função basicamente normativa. Pode-se afirmar que Roget, Dewey, Otlet, Ranganathan, Bliss, Wuster e, mais recentemente, Dahlberg, embora tenham desenvolvido seus sistemas de organização de conceitos em diferentes épocas, o fizeram no interior do cânone do racionalismo moderno.

No contexto da modernidade tardia, porém, a adoção acrítica dos princípios racionalistas pode ser um empecilho para o desenvolvimento de sistemas de organização de conceitos mais adequados à aplicação em sistemas de armazenamento e recuperação de informação. É sobre esta questão, tomando por base as propostas sobre as teorias do conceito e seus possíveis desdobramentos, que daremos seguimento à discussão.

\section{CONCEITOS E CATEGORIAS}

Parte dos dicionários de filosofia apresenta, inicialmente, o termo conceito como "ideia geral" ou "noção abstrata" e quase todos indicam as ambiguidades presentes em sua definição. (RICKEN, 2003; DUROZOI; ROUSSEL, 1996; LALANDE, 1999; 
LEGRANDE, 1991; JAPIASSÚ; MARCONDES, 1995; FERRATER MORA, 2000; BRUGGER, 1977).

Apesar das ambiguidades, os conceitos podem ser contextualizados em duas correntes: no Empirismo, onde os conceitos são construtos que resultam da abstração da experiência; e no Racionalismo, em que os conceitos são produtos da razão. Nessa visão, é conhecida a tradição kantiana, que estabelece distinção entre conceitos puros ou a priori (que não foram retirados da experiência), e os conceitos a posteriori, de natureza empírica.

Segundo Abbagnano (2003, p. 164), um conceito pode ser "[...] todo processo que torne possível a descrição, a classificação e a previsão dos objetos cognoscíveis." De acordo com o autor, esta definição é abrangente e pode "[...] incluir qualquer espécie de sinal ou procedimento semântico, seja qual for o objeto a que se refere, abstrato ou concreto, próximo ou distante, universal ou individual, etc." Os conceitos também podem ser abordados quanto à sua natureza e função. A natureza de um conceito pode estar na essência ou no signo e a função dos conceitos pode ser final ou instrumental.

A concepção do C. [conceito] como essência pertence ao período clássico da filosofia grega, em que o $\mathrm{C}$. é assumido como o que se subtrai à diversidade e à mudança de pontos de vista ou de opiniões, porque se refere às características que, sendo constitutivas do próprio objeto, não são alteradas pela mudança de perspectiva.

[...] C. [conceito] é um signo do objeto (qualquer que seja) e se acha em relação de significação com ele. Por essa interpretação, encontrada pela primeira vez nos estóicos, a doutrina do C. é uma teoria dos signos. (ABBAGNANO, 2003, p.164).

A função, por sua vez,

[...] atribui ao C. [conceito] a interpretação como essência, já que, por essa interpretação, o C. não tem outra função senão exprimir ou revelar a substância das coisas. Desse ponto de vista, a função identifica-se com a própria natureza do conceito. (ABBAGNANO, 2003, p.168).

Ainda de acordo com Abbagnano (2003, p.168), o caráter instrumental do conceito pode comportar outras finalidades:

[...] descrever os objetos da experiência para permitir seu reconhecimento.

[...] econômica. A essa função vincula-se o caráter classificador do C. [conceito].

[...] organizar os dados da experiência de modo que se estabeleçam entre eles conexões de natureza lógica.

[...] previsão. [...] o objetivo de um signo geralmente é prever e a designação de antecipação [...] exprime justamente essa função. 
Para o lógico Newton da Costa, experiência e razão são formas de conhecimento "positivo" que seria o mesmo que conhecimento conceitual; porém, a razão precede a experiência, pois, "[...] fornece as categorias pelas quais sistematizamos nossas sensações e tornamos inteligível a experiência". (COSTA, 1980, p. 3). Dessa forma, ainda segundo Costa, os conceitos:

[...] somente se tornam mais ou menos fixos e estáveis quando são imersos nos contextos racionais, através de termos convenientes cujas conotações eles constituem. Fora de tais contextos, os conceitos se encontram em contínua transformação, dependendo, tanto ao nível subjetivo como ao nível social, de inúmeras circunstâncias, tais como associações de idéias momentâneas e o estado da cultura que se considera. A fixidez dos conceitos nos contextos racionais advém, acima de tudo, de fatores sociais, que impõem certa constância na estrutura dos contextos, tornando-os objetivos. Porém, a priori, nada nos garante que essa objetividade seja absoluta. (COSTA, 1980, p. 4).

Ainda no âmbito da Lógica, Frege (2009) desenvolveu uma espécie de "filosofia do conceito", na qual o

[...] carácter funcional do conceito contribui fundamentalmente para a superação de uma perspectiva psicologista do conceito, como conteúdo ou produto mental, como representação ou como termo final de um processo intelectual abstractivo. (SOARES, 2001, p. 259).

De acordo com Branquinho, Murcho e Gomes (2006, p. 158-160), como os conceitos fregeanos "[...] são uma espécie particular de FUNÇÕES, a distinção conceito/objeto é um caso particular da distinção função/objeto."

Segundo os autores:

Um conceito (Begriff) é aquilo que pode ser definido por, e apenas por, um predicado.

[...] um objeto (Gegenstand) é aquilo que pode ser referido por, e apenas por, um designador ou termo singular [...].

[...] Para Frege, funções - em particular, conceitos - e objetos são, de um lado, categorias de entidades mutuamente excludentes, no sentido em que nenhuma função (nenhum conceito) pode ser um objeto (e vice-versa), e, do outro lado, também categorias conjuntamente exaustivas de entidades, no sentido em que toda e cada coisa ou é uma função ou é um objeto. Trata-se assim de categorias no sentido tradicional do termo: funções e objetos são os genera logicamente primitivos, as classes mais inclusivas nas quais todas as coisas se deixam classificar.

Verifica-se que os conceitos na Lógica têm caráter funcional e operacional, sendo considerados "entidades extra-lingüísticas". (HEGENBERG ,1975, p. 31). Por outro lado, como afirma Campos (2004, p. 24), o tratamento lógico dos conceitos visa à "formalização", não havendo "[...] preocupação com a semântica em termos dos conceitos e de suas relações; na verdade, todo o foco está centrado em uma dada 'sintaxe' que possibilite uma verdadeira ação do pensar [...]." 
No dicionário de Linguística de Crystal (2000) e de Trask (2004) não há registro do termo "conceito". Nesta ciência, a representação simbólica é dada pela ideia de "referente" e "significado".

Encontramos uma discussão sobre o conceito na Semântica de John Lyons. O autor afirma que o conceito é uma ideia, pensamento ou construção mental "[...] por cujo intermédio o espírito apreende ou vem a conhecer coisas [...]." (LYONS, 1980, p. 95). Os conceitos fazem a mediação entre palavras e objetos, portanto, pode-se dizer que o conceito mediador é o elemento de significação. Dessa forma, o conceito está entre o referente e o termo (ou palavra, segundo Lyons) que o designa.

De acordo com Dubois et al (2007, p. 135),

Dá-se o nome de conceito a toda representação simbólica, de natureza verbal, que tem uma significação geral conveniente a toda uma série de objetos concretos que possuem propriedades comuns. (v. referente, significado).

No Dicionário de Semiótica, Greimas e Courtés (1979, p. 70-71) afirmam que:

1. Como termo de filosofia que é, conceito comporta numerosas e variadas definições, todas porém referindo-se mais ou menos a grandezas do significado (= idéias), suscetíveis de organizarem os dados da experiência.

2. F. Saussure serviu-se desse termo para designar - numa primeira aproximação - significado, que tem como única determinação servir para a construção do signo (já que o conceito 'árvore' e a imagem acústica árvore constituem o signo árvore); a seguir, ele eliminou essa noção em benefício da de forma significante.

3. Para a teoria semiótica, o termo conceito pode ser mantido no sentido de denominação (cuja significação é explicitada pela definição). A explicitação dos conceitos por definições sucessivas torna-se então a principal preocupação de qualquer construção metalingüística do teórico. Percebe-se com efeito que as teorias lingüísticas ou semióticas comportam bom número de conceitos nãodefinidos: tomados por empréstimo às línguas naturais e, mais particularmente, às doutrinas filosóficas muitas vezes implícitas, estes são freqüentemente muito sugestivos, suscetíveis de cobrir problemáticas cruciais, mas nem por isso se integram na teoria de conjunto. A construção de uma teoria deve, portanto, comportar uma fase conceptual em que se exige que os conceitos sejam substituídos por definições e interdefinições, cujos elementos constituintes são mais abstratos e mais gerais do que os conceitos de partida. Só no topo de uma tal hierarquia conceptual é que se poderão encontrar conceitos não-definíveis (tais como 'relação', 'objeto', 'descrição', etc.) constitutivos de um inventário que servirá para estabelecer uma axiomática.

4.Vê-se que numa tal concepção de inspiração hjelmsleviana, o termo conceito, elemento da metalinguagem, serve para denominar tanto as classes de objeto (as unidades semióticas) quanto os procedimentos e os modelos. É nesse sentido que se distinguirão no interior de uma teoria conceitos 'reais', isto é, integrados na metassemiótica científica e conceitos operatórios (no sentido de instrumentais) que servem de fundamento a procedimentos ou modelos que parecem eficazes, mas que, não sendo integrados, não podem ser considerados a não ser como provisórios. 
Os pontos de vista apresentados acima estão calcados no que Gardner (2003, p. 360) chama de "visão clássica dos conceitos", porém, segundo o autor, esta visão foi "[...] substituída por uma visão natural dos conceitos."

Por outro lado, tais características são problemáticas quando observadas em seus campos definitórios. Dentre os problemas levantados por Pozzi (1999), nos deteremos em 18 definições terminológicas:

1. Construção mental para classificar objetos individuais do mundo exterior ou interior através de um nível mais ou menos arbitrário de abstração. (ISO R704:1968, revisada em 1986.)

2. Unidade de pensamento produzida pelo agrupamento de objetos individuais relacionados por características comuns. (Proposta DIN).

3. Conjunto coerente de proposições (judgement) sobre um objeto cujo núcleo é composto pelas proposições que refletem as características inerentes do objeto. (Proposta Soviética para a revisão da R704 ISO: 1968).

4. Construções do processo cognitivo humano que auxiliam na classificação de objetos por meio de abstração sistemática ou arbitrária. (SAGER, 1990:22).

5. Construções mentais, abstrações que podem ser usadas para classificar objetos individuais do mundo interior e exterior. (British Standards. BS. 3669:1963).

6. Representação dos objetos de todas as áreas de atividade e conhecimento humanos, como coisas, propriedades, qualidades, fenômenos, etc. (Proposta do Reino Unido para revisão da ISO R 704).

7. Conjunto de características comuns que podem ser observadas pelos seres humanos em certo número de objetos. (Felber, 1982:123).

8. Elemento do pensamento, constructo mental que representa um objeto individual [...] e consta de uma série de características que são comuns a uma classe de objetos individuais. (Cabré, 1993:74).

9. Unidade de conhecimento gerada por uma combinação única de características. (ISO 1087-1, 1999:6).

10. Unidade abstrata que consiste de um número de características de objetos concretos ou abstratos, selecionados de acordo com critérios científicos ou convencionais de um domínio. (de Bessé, Nkwenti-Azeh, Sager, 1997:124).

11. Unidade de pensamento que abarca características comuns destinadas a objetos. (DIN 2342, 1986:6).

12. Unidade de pensamento constituída pelas características que são atribuídas a um objeto ou a uma classe de objetos. (ISO 1087. 1988:2).

13. Elementos comuns que os seres humanos percebem em um grande número de objetos e que utilizam como um meio de classificação mental (para entender) e, por conseguinte, também para comunicar-se. Portanto, o conceito é um elemento de pensamento. (Wüster, 1998:39).

14. Unidade de pensamento que serve para reconhecer objetos, comunicar-se sobre objetos e ordená-los mentalmente. (ONORM A 2704, Entwurf 1989).

15. Resumo (síntese), fixado por uma denominação, de predicados verdadeiros sobre um dado objeto. (Dahlberg, 1976:88). 
16. Unidade de conhecimento que sintetiza em uma forma lingüística os predicados necessários e verificáveis sobre um objeto. (Dahlberg, 1985:40).

17. Representação mental de objetos individuais. (Felber, 1984).

18. Representação mental de objetos dentro de um campo ou contexto especializado. (ISO/DIS 704, 1999:7 [Revisão da segunda edição da ISO 704:1987]).

Na maioria das definições acima, os conceitos se relacionam a atividades mentais: "construções mentais" (definições 1, 4, 5 e 8), "unidades de pensamento" (definições 2, 8, 11, 12, 13 e 14) e "unidades de conhecimento" (definições 6 e 16). (POZZI, 1999).

Os primeiros problemas identificados por Pozzi dizem respeito à ambiguidade e polissemia da palavra "unidade", uma vez que ela tanto pode ser considerada como um processo de pensamento/conhecimento ou uma medida. Nesse caso, pensamento e conhecimento, segundo Pozzi (1999), podem ser considerados sinônimos. A autora analisa as características de cada definição e conclui ser impossível identificar, partindo das dezoito definições acima, "conceitos superordenados" (superordinate concepts) e características essenciais pelas quais o conceito de conceito possa ser descrito inequivocamente. Observa, ainda, que embora apresentem características comuns, se referem a "coisas diferentes", sendo, portanto, "[...] definições de conceitos diferentes." Também lembra que diferentes definições de conceito são dadas por um mesmo autor (Dahlberg, Sager, Felber, ISO), o que demonstra a dificuldade inerente à definição de conceito. Assim, nenhuma definição ou combinação delas é suficientemente clara e aceitável.

Os conceitos, na visão terminológica podem receber outras características:

a) conceito próprio de um domínio: conceito particular ou exclusivo de um domínio;

b) conceito emprestado: conceito que pertence mais especificamente a um outro domínio, mas é igualmente utilizado pelo domínio em estudo. Um exemplo é convés, que tem sua origem no domínio da construção naval e designa os pavimentos a bordo dos navios, mais propriamente os pavimentos descobertos ou semicobertos. Trazido para o domínio da extração petrolífera, designa os espaços abertos das plataformas. Mantém, assim, uma zona de intersecção semântica com o conceito de origem, mas possui traços semânticos que o primeiro não tinha, ou seja, o fato de os espaços abertos encontrarem-se em plataformas petrolíferas;

c) conceito que ultrapassa o domínio: conceito utilizado por vários domínios sem pertencer particularmente a um único. Ex.: embarcar / desembarcar. (BARROS, 2004, p. 107).

Pensando o conceito na área da Organização do conhecimento, ao menos quatro características se sobressaem. Um conceito

- Corresponde a uma unidade de conhecimento; 
- É formado por enunciados verdadeiros e verificáveis;

- Não é metafórico, ambíguo ou plurissignificativo;

- Pertence a um domínio de conhecimento.

No dicionário on line de Organización y representación del conocimiento o conceito é definido como:

Abstracción o noción que refiere a una unidad de conocimiento, independiente de su expresión lingüística, y comprende el conjunto de sus rasgos esenciales. El concepto, en tanto representación simbólica, está en la base de la Teoría de la Clasificación y de la Terminología, pues es el elemento indivisible que permite representar el conocimiento contenido en los documentos y organizar los enunciados correspondientes a la idea que se tiene de cualquier cosa. En vocabularios controlados y en lenguaje natural, el concepto se representa mediante un rótulo. (BARITÉ, 2000, p. 33)

O Guidelines for the construction, format, and management of monolingual controlled vocabularies define o conceito como:

Uma unidade de pensamento, formada pela combinação mental de algumas ou todas as características de um objeto concreto ou abstrato, real ou imaginário. Conceitos existem na mente como entidades abstratas independente dos termos usados para expressa-los. (ANSI/NISO Z39.19, 2005, p. 4)

O conceito é definido nas normas ISO (International Organization for Standardization) como "[...] unidade de conhecimento criada pela combinação única de características" (unit of knowledge created by a unique combination of characteristics) (ISO 1087, 2000, p. 2).

No Dicionário do livro um conceito pode ser:

Qualquer unidade de pensamento. Noção selecionada para reter como unidade de análise semântica, para fins de indexação. $\mathrm{Na}$ indexação os conceitos existentes num documento são extraídos pela análise, que os exprime através de palavraschave. Elemento do pensamento expresso, em geral, por um termo ou por um símbolo literal ou outro. Noção. Preceito; máxima. (FARIA; PERICÃO, 2008, p. 188).

$\mathrm{Na}$ sequência, Faria e Pericão (2008, p. 188) descrevem mais sete tipos de conceitos:

- $\quad$ conceito colateral, definido como conceito associado;

- conceito composto, que se "[...] exprime através de várias palavras";

- conceito específico, que é "[...] específico em relação a outro se este último for genérico do primeiro";

- $\quad$ conceito genérico, "Um conceito é genérico em relação a outro se este último for definido pelos mesmos atributos que o primeiro com um ou vários atributos suplementares";

- $\quad$ conceito geral especial, "Em classificação, subdivisão baseada numa característica que pode aplicar-se à subdivisão de uma classe geral e também às subdivisões dentro dela"; 
- $\quad$ conceito isolado, é um conceito "[...] único que pode ser considerado separadamente para fins de definição ou para ser colocado num sistema de classificação";

- conceito simples, é "Aquele que se exprime através de uma palavra".

Para Piedade, um conceito é a "[...] operação da inteligência através da qual se apreendem os caracteres essenciais daquilo que se conhece. É a representação mental do que se sabe, uma idéia, uma coisa, um julgamento etc." (PIEDADE, 1983, p. 35)

Nota-se, nas definições acima, a predominância de princípios lógicos. Quase todas se referem a objetos e seus atributos (características). Evidencia-se aqui o processo classificatório, na medida que classificar pode significar colocar uma coisa ou uma ideia recém conhecida entre outras coisas ou ideias já conhecidas, separando entidades por nível de semelhança. (VICKERY, 1980; PIEDADE, 1983; CAMPOS, 1973). A classificação opera por comparação entre as características das coisas, estabelecendo um princípio de ordem que obedece a um conjunto complexo e dinâmico de inferências.

As categorias são, por sua vez, metaconceitos que nomeiam agrupamentos de termos de uma determinada área. Nesse sentido, "[...] denominam-se categorias as classes que resultam da divisão do universo de conhecimentos, de acordo com as características intrínsecas ou fundamentais de cada conceito" (CAVALCANTI, 1978, p. 15).

Os agrupamentos manifestam, frequentemente, particularidades em relação às áreas de conhecimento consideradas, às aplicações pretendidas pela linguagem documentária ou ao tipo de informação a ser organizada. Assim sendo, as categorias não constituem dados universais. Ao contrario, nomeiam agrupamentos feitos de acordo com propósitos institucionais: são agregados que obedecem a um ponto de vista.

As teorias da classificação propõem uma lista de categorias tendo em vista a formulação de um quadro geral de referência. Evita-se a construção de grupos inconsistentes pela adoção de critérios explícitos. Nessa concepção, as categorias devem agrupar conjuntos mutuamente exclusivos. Este é um pressuposto essencial para a operação consistente de sistemas de informação. A ordenação sistemática dos conceitos em categorias gera um sistema de conceitos, ou seja, conceitos relacionados entre si (GOMES, 1990).

Os sistemas de conceitos valem-se de princípios lógicos para organizá-los, pois são, em certa medida, representados pelas teorias clássicas de organização de conceitos como as de Ranganathan, Wüster e Dalhberg (CAMPOS, 1995). Dessa forma, na 
tentativa de imprimir consistência aos sistemas de organização de conceitos, teorias, metodologias e ferramentas foram desenvolvidas para operacionalizá-los e um núcleo transdisciplinar, e por que não dizer "canônico", de estudos sobre a análise e tratamento de conteúdos de documentos foi consolidado.

Como indicamos na introdução, diversos pensadores desenvolveram seus sistemas de organização de conceitos sob o cânone da consistência. Destacamos Ranganathan, considerado o "pai da moderna teoria da classificação" (DAHLBERG, 1979), e o primeiro a propor a noção de categoria na classificação (CAMPOS; GOMES, 2007).

Ranganathan se preocupou em esclarecer, segundo Campos e Gomes (2003, p. 152), as bases teóricas da Colon Classification incorporando um "status" de disciplina independente à Classificação. Ranganathan explica a formação dos conceitos no universo do conhecimento em etapas "mentais" de perceptos do mundo físico. A lógica subjacente à sua teoria indica que o conceito se estabelece em uma sequência de etapas, recortes, enfim, "fatias" que determinam o movimento contínuo e infinito de sua Espiral do Universo do Conhecimento. Para Ranganathan (1967 apud CAMPOS; GOMES, 2003, p. 153-154), o universo do conhecimento é

[...] 'a soma total, num dado momento, do conhecimento acumulado. Ele está sempre em desenvolvimento contínuo. Diferentes domínios do Universo do Conhecimento são desenvolvidos por diferentes métodos. O Método Científico é um dos métodos reconhecidos de desenvolvimento. O Método Científico é caracterizado pelo movimento sem fim em espiral [...].'

Porém, Ranganathan não exclui a ideia de complexidade na relação entre conceitos, ilustrando-a por meio da árvore Baniana, que prevê a relação entre vários domínios, em contraposição à tradicional árvore dicotômica de Porfírio, na qual os domínios estão contidos em outros domínios, sucessivamente. Na árvore Baniana "Os ramos de um tronco se enxertam em outros de outro tronco. É difícil dizer a que tronco pertencem tais ramos. Os troncos se enxertam entre si." (RANGANATHAN, 1967 apud CAMPOS; GOMES, 2003, p. 158).

Para Campos e Gomes (2003, p. 159), a "[...] representação da árvore Baniana apresentada por Ranganathan vem ao encontro do conceito de rizoma de Deleuze e Guattari [...]". Este é um aspecto a ser considerado nesta discussão. Deve-se lembrar, no entanto, que para Deleuze e Guattari somente a Filosofia cria conceitos; a ciência, ao contrário, atua por proposições e enunciados sobre objetos. Ou seja: 
À ciência cabe buscar a referência do conceito, ou melhor, sua função é extensiva, ao passo que a Filosofia é intensiva justamente porque cria os conceitos. Ora, no plano de referência está a figura, o objeto e a explicação desses objetos. Assim ocorre que a ciência é discursiva e suas proposições não devem ser confundidas, segundo os autores supracitados [Deleuze e Guattari], com os conceitos, mas antes, são explicações das funções acerca dos conceitos ou com os estados de coisas no qual se encarnam.

A Filosofia pensa por conceitos, a ciência por figuras, que são essencialmente projetivas, paradigmáticas, hierárquicas e referenciais, em contrapartida, os conceitos são conectivos, sintagmáticos, vicinais e consistentes. (MONTEIRO, 2007, p. 1)

Estabelece-se, dessa forma, uma contradição: se para Deleuze e Guattari, só a Filosofia cria conceitos, como compreender a posição de Ranganathan, para quem o "método científico" é um dos responsáveis pelo desenvolvimento do universo do conhecimento? Os conceitos criados pelo método científico é que deveriam ser consistentes, já que são eles os responsáveis pelo movimento infinito da Espiral do Universo do Conhecimento.

Entre Ranganathan e Deleuze e Guattari existem diferenças temporais, culturais, sociais e filosóficas marcantes e objetivos distintos. No entanto, como observaram Campos e Gomes (2003), é possível ver semelhanças entre a "representação da árvore Baniana", de Ranganathan, e o "conceito de rizoma", de Deleuze e Guattari. Tanto a árvore Baniana quanto o rizoma são metáforas para representar de forma "holística" a organização do complexo por meio da metáfora da "árvore" (COSTA, 1996). Esses conceitos estão atualmente relacionados à ideia de rede (FERREIRA, 2008; MONTEIRO, 2003; GOMES; MOTTA; CAMPOS, 2006).

\section{OPERACIONALIZAÇÃO DE CONCEITOS}

Nos processos de tratamento e recuperação da informação, o conceito, tanto na etapa de análise do documento, quanto na tradução com fins de padronização, ocupa lugar central. Um sistema de recuperação de informação prevê duas abordagens fundamentais: a análise chamada "física" ou "descritiva" do documento (quando são descritos dados bibliográficos, como autoria, editora, número de páginas, ano de publicação, etc); e a análise de "conteúdo" ou "temática" do documento (em que o conteúdo do documento é representado por meio de conceitos (termos)). A representação física de um documento pode ser comum em diferentes sistemas, mas a representação temática pode variar. A figura de Cesarino e Pinto (1980, p.33) ilustra a centralidade do conceito no sistema de recuperação de informação: 


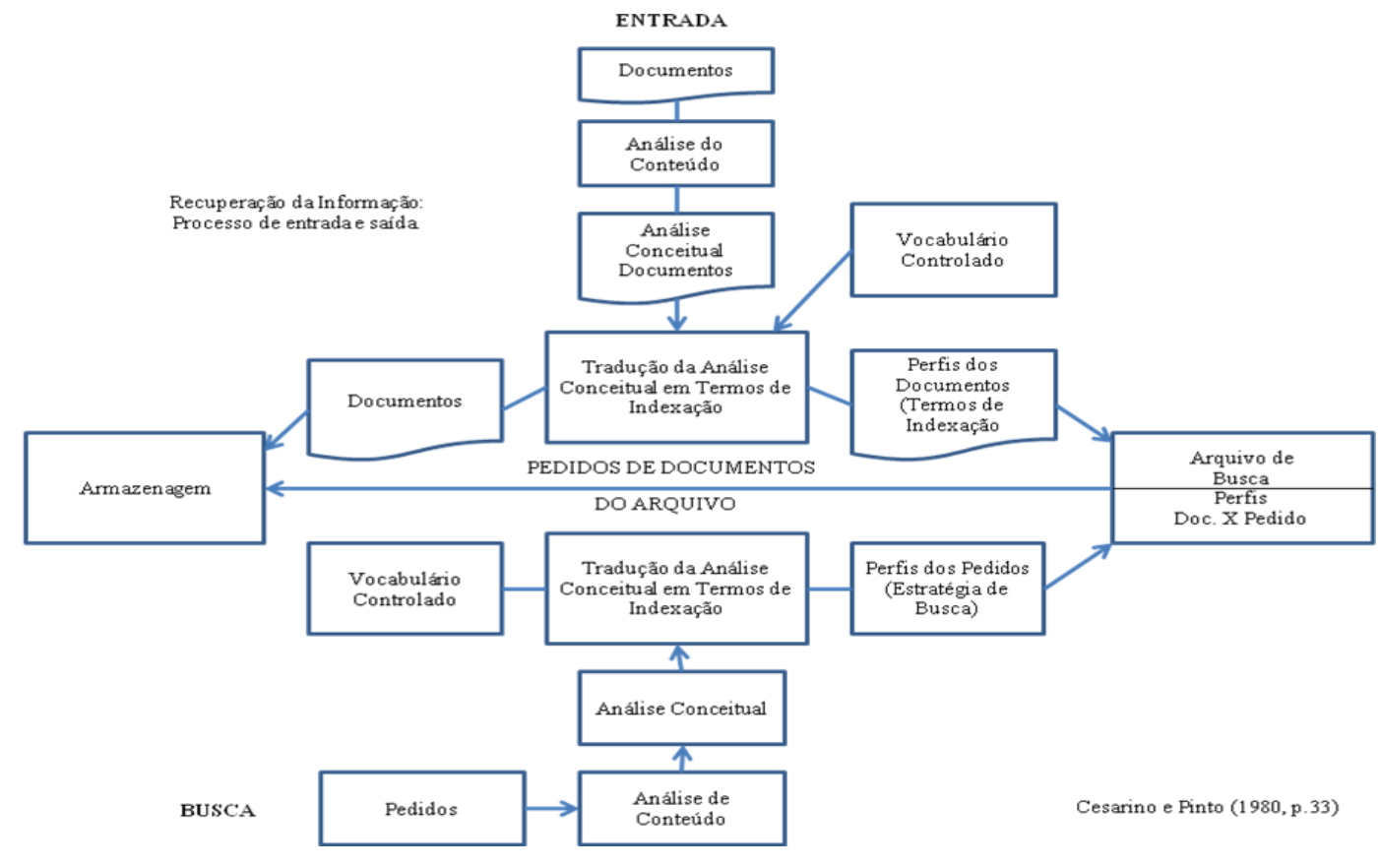

A construção de sistemas de recuperação de informação depende de uma forma de metalinguagem, chamada linguagem artificial ou documentária. De acordo com Kobashi (1994, p. 54-56) e Cintra et al (2002, p. 34), a função das Linguagens Documentárias, enquanto sistemas simbólicos de comunicação, restringe-se ao uso em ambientes documentários. São linguagens intermediárias, reduzidas, sem as características da Linguagem Natural, que têm papel de destaque na comunicação usuário-sistema de informação.

As Linguagens Documentárias não comportam, como afirmam Chaumier (1973, p. 52), Kobashi (1994, p. 56) e Cintra et al (2002, p. 35), a "riqueza" e o "poder expressivo" da Linguagem Natural devido à precariedade de seus mecanismos de articulação, porém, são eficazes nos processos de produção e recepção de informações.

Por outro lado, as Linguagens Documentárias não têm a função apenas de significar, mas de significar de maneira precisa com o objetivo último de representar e recuperar informação. Elas podem ser definidas como um "[...] conjunto de termos, providos ou não de regras sintáticas, utilizadas para representar conteúdos de documentos técnico-científicos [...]" (CINTRA et al, 2002, p. 35), ou seja, são usadas para representar conceitos. Ao operar dentro de um sistema, a linguagem documentária reduz a extensão semântica do conceito, definindo-o como "unidade" de conhecimento, deslocando-o de seu uso social para o uso no sistema de informação. 
Quando um conceito é retirado de seu ambiente de uso social ou contextual e colocado no ambiente do sistema, ele passa de uma categoria discursiva, dinâmica e plurissignificativa, para outra, fixa e monossignificativa. Há, nesse movimento, perda de conteúdo semântico na transferência do contexto de uso do conceito para o contexto de controle do conceito para recuperação de informação.

Geralmente, a operação de transferência de conceitos é realizada a partir de campos técnicos e científicos. Os conceitos técnicos e científicos são usados por uma comunidade especializada com mínima variação semântica. Eles formam o sistema nocional de uma área de conhecimento.

"Noção" pode ser tomada como conceito na perspectiva da ISO 1087. Um conjunto de noções (conceitos) corresponde ao que se chama sistema nocional. Os sistemas nocionais são a base da organização do conhecimento de uma determinada área de especialidade. Em decorrência, um sistema nocional (de conceitos) organizado promove também a eficácia dos instrumentos de tratamento e recuperação da informação. A ausência de um sistema nocional dificulta 0 arranjo dos termos em uma linguagem documentária pela falta de compreensão "[...] ou da compreensão incorreta das possibilidades de relacionamento entre termos." (CINTRA et al, 2002, p. 49). Assim, para Cintra et al (2002, p. 49) o sistema nocional de uma área é uma "viga-mestra" que sustenta as Linguagens Documentárias.

Além das dificuldades para apreender o significado dos termos, a ausência de um sistema nocional (de conceitos) organizado, também coloca problemas às operações documentárias realizadas por indexadores, pois, um sistema nocional desorganizado ou disperso permite variações de entendimento e interpretação, o que pode induzir ao erro e/ou deformações nos "instrumentos documentários". De acordo com a ISO 1087 (apud CINTRA et al, 2002, p. 50) um sistema nocional é definido "[...] como um "conjunto estruturado de noções que reflete as relações estabelecidas entre as noções que o compõem e no qual cada noção é determinada pela sua posição no sistema"'. As autoras lembram ser necessário, além de identificar as noções e recuperá-las, definir posições e relações de associação.

No âmbito documentário, dois tipos de relações são consideradas importantes: hierárquicas e não-hierárquicas. As relações hierárquicas são "[...] aquelas que acontecem entre termos de um conjunto, onde cada termo é superior ao termo seguinte, por uma característica de natureza normativa." (CINTRA et al, 2002, p. 51). Já as relações 
não-hierárquicas não supõem uma hierarquia, mas uma relação espacial ou temporal. A organização dos conceitos em hierarquias determinadas depende, segundo as autoras, de aspectos localizados, como pontos de vista particulares, questões ideológicas e culturais. De acordo com Cintra et al (2002, p. 58), a organização de conceitos e a configuração de Linguagens Documentárias estão baseadas nas "propriedades das palavras" e não nas coisas. Nesse sentido, o que se organiza em hierarquias determinadas são conceitos e palavras a partir de eventos definidos (como pontos de vista e implicações sócio-culturais e ideológicas) e não as coisas "no mundo".

Para Alvarenga (2003, p. 22), essa forma de representação, “[...] secundária teria por objeto prioritário não o acervo da ontologia, das coisas e seres existentes, mas o acervo de conhecimentos sobre essas coisas e seres, objetos da epistemologia." A epistemologia estuda os conhecimentos já registrados. Dessa maneira, a organização dos saberes influencia a estrutura de organização dos documentos, fundamental, por sua vez, na configuração epistemológica de uma área.

Sob essa ótica, estamos mais próximos do cânone epistemológico do que do cânone ontológico. A epistemologia não opera diretamente com objetos. Seu âmbito é o do conhecimento produzido sobre objetos. O contato direto das coisas e dos seres, entre suas partes e seu todo, é objeto da ontologia. A ontologia procurar explicar a cadeia de relações entre seres e coisas dentro de seus universos naturais, ou seja, dentro do ambiente da existência. Seres e coisas são classificados em hierarquias de acordo com características primárias do objeto. Com a análise do objeto em relação a outros objetos, características the serão atribuídas, fornecendo elementos para a construção de um conceito.

O processo de formação conceitual pode exigir mudanças na hierarquia, imprimindo deslocamentos na cadeia ontológica primária. Dentro do conhecimento já produzido e organizado, os conceitos em formação são alocados de modo a compor a macroestrutura conceitual consolidada em distintas áreas do saber. Nessa perspectiva, devem ser lembrados os estudos de classificação automática, conhecidos na literatura por "clustering" (KAUFMAN; ROUSSEEUW, 1990), técnica utilizada não apenas para identificar a estrutura presente em dados, mas também para impor uma estrutura a dados mais ou menos homogêneos. O "clustering" de conceitos, atividade importante nos estudos cientométricos, obedece a critérios semânticos e estatísticos que devem, de 
nosso ponto de vista, ser mais amplamente explorado por aqueles que atuam no campo da Organização do conhecimento.

Por fim, são os documentos os objetos que compõem o universo de legitimação destes saberes. Através deles os saberes, constituídos de conceitos formalmente localizados tornam-se públicos, constituindo uma nova forma de representação.

\section{A GUISA DE CONCLUSÃO: NOVOS CÂNONES NAS TEORIAS DO CONCEITO}

Em sentido dicionário, as teorias podem ser conhecimentos racionais de base especulativa (HOUAISS, 2001). No caso das teorias científicas as especulações são feitas com certo embasamento para terem poder de convencimento. Quase tudo o que se sabe sobre o homem e a natureza teve como ponto de partida alguma especulação que, fundamentada, pode convencer indivíduos, grupos, e assim ganhar universalidade.

A força das teorias é medida pela sua evolução no tempo histórico e grau de influência nos campos de conhecimento. $O$ racionalismo e o empirismo, são os dois grandes ramos teóricos seculares que estão na base das ciências, dentre as quais, a Ciência da Informação. De base racionalista, com raízes nas lógicas aristotélica, kantiana e fregeana, as teorias da Classificação e do Conceito tornaram-se universais. Nelas, como visto acima, estão as premissas de efeito normativo para a organização de conceitos em sistemas de recuperação da informação. Porém, como procuramos mostrar, outras discussões, como aquelas desenvolvidas no campo da Terminologia e das Linguagens Documentárias introduziram discussões sobre os limites dos cânones normativos.

Para nós, tais discussões não se limitam, portanto, à verificação de métodos operacionais, mas à questões epistemológicas do próprio campo da Organização do conhecimento. Com efeito, se pensarmos em características únicas e enunciados verdadeiros como elementos de uma unidade de conhecimento, ou seja, de um conceito, estamos de acordo com a ideia de paradigma de domínio na concepção canônica de Thomas Kuhn. Mas se aceitamos que estamos em um momento pós-kuhniano, em que os paradigmas coexistem num mesmo espaço, sem que haja o domínio de um e único paradigma, então podemos afirmar que há um novo contexto epistemológico, isto é, há novas formas possíveis de produção, comunicação, análise e organização do conhecimento. 
Recentemente, Birger Hjørland expôs, no artigo "Concept Theory", a influência de correntes paradigmáticas e epistemológicas sobre o conceito. Na perspectiva adotada pelo autor haveria concomitância de paradigmas, ou seja, prevaleceria a perspectiva póskuhniana de convivência e relação entre teorias e paradigmas distintos sobre o desenvolvimento e organização de conceitos. Segundo Hjørland (2009), a complexidade e a interdisciplinaridade que envolvem as discussões sobre o conceito demandam novos pontos de vista, tal como o pragmatista e o historicista. De fato, o que as teorias do conceito demonstram é a falta de consenso sobre o que são conceitos. Seguindo esse raciocínio, deve-se admitir que os sistemas de organização do conhecimento, (sistemas de classificação, tesauros e ontologias), entendidos como sistemas de organização de conceitos, operam, na maioria das vezes, de maneira irrefletida, sem explicitar a teoria subjacente à sua construção.

Quando Hjørland associa "paradigmas" e "conceitos" deixa claro que a noção de um único paradigma dominante, como ideia central do sistema kuhniano, não se adequa aos sistemas multifacetados, "rizomáticos" e complexos que estão na base das teorias do conhecimento contemporâneas. O paradigma pós-kuhniano, como dito acima, permite a convivência de distintas teorias em um mesmo domínio. Então, além dos fundamentos lógico-semânticos de base positivista ou analítica, outras correntes epistemológicas, como o empirismo, o racionalismo, o historicismo e o pragmatismo, poderiam ser usadas teórica e metodologicamente em pesquisas sobre os conceitos.

Um exemplo dado pelo autor dinamarquês é a visão cognitiva, adotada pela Ciência da Informação nas décadas de 1980 e 1990, em que os conceitos são "arquivos" na memória humana. Hoje, essa visão vem sendo posta em questão pelas ciências cognitivas, as quais procuram integrar os aspectos históricos e culturais na formação de conceitos. Em resumo, o argumento principal de Hjørland (2009, p. 1520): "A shift in the understanding of concepts is part of a broader shift in our understanding of cognition, knowledge, and information" se impõe nos estudos de organização da informação e do conhecimento. A mudança na compreensão dos conceitos faz parte, portanto, de um movimento de melhor compreensão da cognição, do conhecimento e da informação. Essas noções estão em pleno processo de estudos, particularmente nas teorias e metodologias relacionadas à rede.

Os principais cânones da organização de conceitos foram historicamente sedimentados, alguns deles são seculares, e não tinham a dimensão do que se entende 
por informação e conhecimento na contemporaneidade. Da mesma forma, não se pode prever que paradigmas nortearão as pesquisas sobre esses objetos ou fenômenos nas próximas décadas. O que se pode fazer é desenvolver análises, especulativas no início, porém, visando ao discurso científico, que busquem a melhor forma de explicar e argumentar dentro de um determinado contexto de conhecimento. Assim, metáforas como as de "árvore" e de "rizoma" são criadas e uma analogia entre elas é possível. As analogias e as incursões transdisciplinares no campo do tratamento de conteúdos documentais são exemplos práticos das questões epistemológicas sobre as teorias do conceito levantadas por Hjørland. Por outro lado, é evidente que existem problemas na abordagem dos conceitos. Elegemos dois como os mais significativos no momento:

- Primeiro, pelas teorias gerais dos conceitos, estes problemas são identificados quando se tenta compilar todos os seus cânones. Uma cobertura que tenha início em Platão, Aristóteles, Descartes, Leibniz, Kant até chegar aos filósofos contemporâneos, indicará, certamente, a existência de lacunas. Hjørland comenta uma tentativa de compilar cânones conceituais, tendo identificado as lacunas no tratamento dado a Platão e Aristóteles e a ausência de cânones contemporâneos como a "história dos conceitos", a "teoria da atividade", a "hermenêutica", a "teoria dos atos da fala" e o "pragmatismo". $\mathrm{Na}$ mesma linha, há omissões em torno das teorias probabilísticas (prototípicas) dos conceitos, das teorias baseadas em teorias dos conceitos (theory-based theories of concepts), das teorias neoclássicas dos conceitos e do atomismo conceitual.

- Há, por outro lado, dificuldades para detectar como os conceitos são definidos nos domínios científicos. O exemplo clássico, neste caso, é comparar conceitos da física e da matemática com conceitos filosóficos e sociais. Hjørland cita Chalmers, que compara o conceito de massa newtoniano com o de democracia, dizendo que aquele é mais preciso do que este. Porém, Hjørland fixa sua atenção no léxico, afirmando que definir conceitos somente através de outros conceitos disponíveis não parece suficiente. Segundo Hjørland (2009, p. 1521) Newton talvez não tenha podido definir os termos "massa" ou "força" com os conceitos disponíveis à época. Foi necessário certo tipo de "transcendência" do antigo quadro conceitual. ("Newton could not define mass or force in terms of previously available concepts. It was necessary for him to transcend the limits of the old conceptual framework by developing a new one.").

Observa-se, portanto, que todas as teorias são, em certo sentido, teorias do conceito, ou seja, todo conhecimento acumulado é também acúmulo de conceitos. Não é possível 
saber que fatores cognitivos, sociais ou históricos têm influência na criação de um conceito, por um filósofo, quando este se encontra no alto de uma montanha ou diante de uma pedra ou quando um cientista olha para o céu ou para uma maçã que cai. No entanto, todo tipo de conhecimento é uma tentativa de entender objetos e fenômenos naturais e humanos; a explicação deste processo de entender objetos e fenômenos é, por extensão, a tentativa de explicar o processo de criação, formação e desenvolvimento de conceitos. As teorias do conhecimento são construídas nesse processo contínuo de especulação e explicação.

Os cânones do conhecimento foram instituídos por grupos, indivíduos, instituições e, em quase todos os momentos de uma história descontínua de desenvolvimento filosófico e científico, há emergência de novos cânones e a concorrência entre eles. Quando um cânone é estabelecido e aceito por um grupo ou uma sociedade, é evidente que a tentativa de mudá-lo parcialmente ou totalmente é um processo complexo, pois, os conceitos fixam-se e se estabilizam em contextos sócio-históricos que nem sempre são bem definidos. Hjørland (2009, p. 1522), com base na Teoria da Atividade, afirma que a estabilidade dos conceitos depende da padronização de práticas sociais e a mudança de um conceito implica a mudança de algum padrão ou prática. Conceitos alternativos emergem indicando a insuficiência dos conceitos padrão vigentes ou complementando-os com novas teorias. Para Hjørland, quatro pontos de vista epistemológicos estão presentes em quase todos os domínios de conhecimento. São eles: o empirismo, o racionalismo, o historicismo e o pragmatismo. Como são suficientemente analisados e discutidos na literatura, especialmente por Hjørland, reproduzimos a seguir um resumo sobre estes pontos de vista sobre o conceito:

We have now seen that four distinctly different ways of understanding concepts are related to four epistemological views:

- The ideal of empiricism is to define concepts by clustering similar objects (relying on features that can be observed 'objectively' and avoiding theoretical selection of defining properties).

- The ideal of rationalism is to define concepts by a set of primitive concepts (or 'semantic primitives') considered 'given.'

- The ideal of historicism is to define concepts (a) genealogically and (b) by explicating their relations to theories and discourses.

- The ideal of pragmatism is to define concepts by deciding which class of things best serves a given purpose and then to fixate this class in a sign. (HJØRLAND, 2009, p. 1527). 
O ponto fundamental a ser ressaltado nos "ideais" ou cânones epistemológicos citados acima é aquele que indica os cânones que sedimentam o campo da Ciência da Informação. Nas palavras de Hjørland (2009, p. 1529):

\begin{abstract}
Any view of concepts in information science is, of course, related to the overall approach to the field. If information scientists are mainly influenced by empiricism and rationalism, then their corresponding views of concepts tend also to be influenced by empiricism and rationalism. If information scientists, on the other hand, are influenced by hermeneutics or other social/historical epistemologies, then their corresponding understanding of the term 'concept' tends to reflect such a social and historical view.
\end{abstract}

As influências epistemológicas dos "cientistas da informação" poderão determinar os pontos de vista que serão lançados sobre os conceitos. Um exemplo dado por Hjørland por explicitar melhor a questão: a bibliometria é empírica quando busca a frequência de conceitos; é racionalista quando cria categorias conceituais e procura semelhanças entre as características dos conceitos; é historicista quando tenta fazer uma genealogia dos conceitos; e a visão pragmática busca entender fatores ou valores que estão presentes no uso dos conceitos.

Aceitar que as influências epistemológicas são importantes na maneira de assumir posições teóricas e metodológicas diante do entendimento e do tratamento de conceitos não é difícil, pois, esta é uma espécie de dogma, presente e necessário em todas as áreas de conhecimento, como já indicou Kuhn (1979). Sem posições definidas e publicamente assumidas o desenvolvimento e a comunicação adequada de conhecimento seria impossível. O que muda é que este dogma ou, como preferimos, este cânone não incide diretamente sobre os objetos e fenômenos estudados pela ciência. De forma mais objetiva, um pesquisador formado no cânone racionalista será, evidentemente, propenso a analisar fenômenos e objetos a partir deste cânone e o inverso será verificado em um pesquisador formado no cânone pragmatista, pois, estes são seus universos de especialidade e, de certa maneira, de "comodidade". Porém, como já disse Bachelard, o "incômodo" é um dos principais responsáveis pela evolução do conhecimento.

É interessante pensar que os cânones dão segurança e estabilidade ao conhecimento e também aos conceitos, mas, a construção de novos conhecimentos e conceitos possivelmente dependerá de uma espécie de "transgressão" dos limites estabelecidos. Geralmente, a solução de uma situação "incômoda" depende da apropriação ou agregação de novos conhecimentos, ou seja, novos cânones deverão ser analisados e, se necessário, incorporados para a busca de um novo patamar de "normalidade". Mas, este não é um processo linear e, muito menos, contínuo. Pode ser 
cíclico, facetado, caótico, rizomático, anárquico, complexo, holístico, etc; só não é estático.

Concluímos, por fim, concordando com Hjørland sobre a necessidade de se estabelecer cânones epistemológicos sociais como base dos estudos dos conceitos. Para o autor,

The view of concepts presented in this article is clearly social. Concepts have been understood as socially negotiated meanings that should be identified by studying discourses rather than by studying individual users or a priori principles. The implication of the presented view of concepts, thus, calls for an argument both as to why the social point of view is important and for the role of concept theory in the fulfillment of the potentials of a social turn in information science. (HJØRLAND, 2009, p. 1530).

Muitos pesquisadores vêm discutindo e analisando possibilidades de adaptação, desenvolvimento e construção de teorias e métodos que forneçam bases mais consistentes para a organização de conceitos em sistemas de recuperação da informação. Podemos identificar na literatura brasileira, o "incômodo" permanente diante de questões cognitivas, sociais e culturais quando o assunto passa pelo cânone normativo de conteúdos documentais.

Além do aporte teórico e técnico norte americano, nossas bases epistemológicas tiveram forte influência européia, especialmente da escola francesa. No entanto, notamos que a síntese de teorias do conceito, proposta por Hjørland, desconsidera os cânones europeus de análise de conteúdos documentais. Contribuições como as de Gaston Bachelard, Gilles-Gaston Granger, Deleuze e Guattari e Michel Foucault são fundamentais para a discussão da formação dos conceitos na ciência, suas relações com a lógica e com a linguagem e, principalmente, a "potência" que os conceitos adquirem na dinâmica do discurso das ciências. Esses temas têm sido objetos de especulação da Teoria Comunicativa da Terminologia, da Socioterminologia e da Linguística Documental, dentre outras, porém, essas teorias não estão presentes nas análises de Hjørland. Desse modo, acreditamos que às contribuições recentes de Hjørland devem ser agregadas as pesquisas de autores brasileiros, alguns deles citados no presente texto, por serem elas fundamentais para compreender muitos aspectos epistemológicos da Organização da Informação e do Conhecimento.

\section{REFERÊNCIAS}

ABBAGNANO, Nicola. Dicionário de Filosofia. 4.ed. São Paulo: Martins Fontes, 2003. 
ALVARENGA, Lídia. Representação do conhecimento na perspectiva da ciência da informação em tempo e espaço digitais. Encontros Bibli: revista eletrônica de Biblioteconomia e Ciência da Informação, Florianópolis, v. 8, n. 15, 1 sem. 2003. Disponível em: <http://www.periodicos.ufsc.br/index.php/eb>. Acesso em: 02 out. 2008.

ANSI/NISO Z39.19. Guidelines for the construction, format, and management of monolingual controlled vocabularies. Maryland: NISO, 2005.

ARMENGAUD, F. A pragmática. São Paulo: Parábola, 2006.

BARITÉ, Mario. Diccionario de organización y representación del conocimiento: clasificación, indización, terminologia. Uruguai: s.e., 2000. Disponível em: <http://www.eubca.edu.uy/diccionario/index.htm>. Acesso em: 25/06/2008.

BARROS, Lidia de Almeida. Curso básico de Terminologia. São Paulo: Edusp, 2004.

BRANQUINHO, João; MURCHO, Desidério; GOMES, Nelson Gonçalves. (Eds.) Enciclopédia de termos lógico-filosóficos. São Paulo: Martins Fontes, 2006.

BRUGGER, Walter. Dicionário de Filosofia. 3. ed. São Paulo: EPU, 1977.

CAMPOS, Astério. O nascer de uma utopia: ainda e sempre o problema da classificação bibliográfica. Revista de Biblioteconomia de Brasília, v.1, n.1, p.15-19, jan./jun. 1973.

CAMPOS, Maria Luiza de Almeida. Modelização de domínios de conhecimento: uma investigação de princípios fundamentais. Ciência da Informação, Brasília, v.33, n.1, p.2232, jan./abr. 2004. Disponível em: <http://revista.ibict.br>. Acesso em: 02 de out. 2008.

CAMPOS, Maria Luiza de Almeida. Perspectivas para o estudo da área de representação da informação. Ciência da Informação, Brasília, v.25, n.2. 1995. Disponível em: <http://revista.ibict.br>. Acesso em: 02 de out. 2008.

CAMPOS, Maria Luiza de Almeida; GOMES, Hagar Espanha. Organização de domínios de conhecimento e os princípios ranganathianos. Perspectivas em Ciência da Informação, Belo Horizonte, v.8, n.2, p.150-163, jul./dez. 2003. Disponível em: $<$ http://portaldeperiodicos.eci.ufmg.br/index.php/pci/article/viewFile/366/175>. Acesso em: 02 de out. 2008.

CAMPOS, Maria Luiza de Almeida; GOMES, Hagar Espanha. Taxonomia e classificação: a categorização como princípio. In: VIII Encontro Nacional de Pesquisa em Ciência da Informação. Anais... Salvador, 2007.

CASTELLS, Manuel. A sociedade em rede. 11.ed. São Paulo: Paz e Terra, 2008. (A era da informação: economia, sociedade e cultura; v.1).

CAVALVANTI, Cordelia R. Indexação \& Tesauro: metodologia \& técnicas. Brasília: Associação de Bibliotecários do Distrito Federal, 1978.

CESARINO, Maria Augusta da Nóbrega; PINTO, Maria Cristina Mello Ferreira. Análise de assunto. Revista de Biblioteconomia de Brasília, v.8, n.1, p.32-43, jan./jun. 1980. 
CHAUMIER, Jacques. As técnicas documentais. Lisboa: Europa-América, 1973. (Coleção Saber, n.72).

CINTRA, Anna Maria Marques et al. Para entender as linguagens documentárias. 2.ed. São Paulo: Polis, 2002.

COSTA, Icléia Thiesen Magalhães. Memória institucional e representação: do mundo das formas (árvore) ao universo do pensamento (rizoma). Informare, v.2, n.2, p.67-72, jul./dez. 1996. Disponível em: <http://ibict.phlnet.com.br/anexos/costav2n2.pdf>. Acesso em: 20 de jul. 2011.

COSTA, Newton C. A. da. Ensaio sobre os fundamentos da lógica. São Paulo: Hucitec/EDUSP, 1980.

CRYSTAL, David. Dicionário de linguística e fonética. Rio de Janeiro: Jorge Zahar Editor, 2000.

DAHLBERG, Ingetraut. Teoria da Classificação, ontem e hoje. Tradução Henry B. Cox. In: Conferência Brasileira de Classificação Bibliográfica, 1972, Rio de Janeiro. Anais... Brasília: IBICT/ABDF, 1979. v.1. p. 352-370. Disponível em: $<$ http://www.conexaorio.com/biti/dahlbergteoria/index_teoria.htm>. Acesso em: 02de out. 2005.

DUBOIS, Jean. et al. Dicionário de linguística. 8.ed. São Paulo: Cultrix, 2007.

DUROZOI, Gérard; ROUSSEL, André. Dicionário de Filosofia. Campinas: Papirus Editora, 1996.

FARIA, Maria Isabel; PERICÃO, Maria da Graça. Dicionário do livro: da escrita ao livro eletrônico. São Paulo: EdUSP, 2008.

FERRATER MORA, José. Dicionário de Filosofia. São Paulo: Edições Loyola, 2000. (Tomo I).

FERREIRA, Flávia Turino. Rizoma: um método para as redes? Liinc em Revista, v.4, n.1, p.28-40, mar. 2008.20 Disponível <http://revista.ibict.br/liinc/index.php/liinc/article/viewFile/251/142>. Acesso em: 20 de jul. 2011.

FRANCELIN, Marivalde Moacir. Ordem dos conceitos na Organização da Informação e do Conhecimento. São Paulo: ECA/USP, 2010. (Tese de Doutorado).

FREGE, Gottlob. Lógica e filosofia da linguagem. 2.ed. São Paulo: EdUSP, 2009.

GARDNER, Howard. A nova ciência da mente. 3.ed. São Paulo: Edusp, 2003.

GOMES, Hagar Espanha. Manual de elaboração de tesauros monolíngües. Brasília: Programa Nacional de Bibliotecas de Instituições de Ensino Superior, 1990.

GOMES, Hagar Espanha; MOTTA, Dilza Fonseca da; CAMPOS, Maria Luiza de Almeida. Revisitando Ranganathan: a classificação na rede. 2006. Disponível em: <http://www.conexaorio.com/biti/revisitando/revisitando.htm>. Acesso em: 09 de jul. 2011. 
GREIMAS, Algirdas Julien; COURTES, Joseph. Dicionário de semiótica. São Paulo: Cultrix, 1979.

HEGENBERG, Leônidas. Significado e conhecimento. São Paulo: EPU/EDUSP, 1975.

HJØRLAND, Birger. Concept theory. Journal of the American Society for Information Science and Technology, v. 60, n. 8, p. 1519-1536, 2009.

HOUAISS, Antônio. Dicionário Houaiss da língua portuguesa. Rio de Janeiro: Objetiva, 2001.

ISO 1087. Terminology work - vocabulary - Part 1: Theory and application. Switzerland: ISO, 2000.

JAPIASSÚ, Hilton; MARCONDES, Danilo. Dicionário de Filosofia. 3.ed. Rio de Janeiro: Jorge Zahar Editor, 1995.

KAUFMAN, Leonard; ROUSSEEUW, Peter J. Finding groups in data: an introduction to cluster analysis. New York: John Wiley, 1990.

KOBASHI, Nair Yumiko. A elaboração de informações documentárias: em busca de uma metodologia. São Paulo: USP, 1994. (Tese de Doutorado).

KUHN, Thomas. A função do dogma na investigação científica. DEUS, Jorge Dias de. (Org.). A crítica da ciência: sociologia e ideologia da ciência. 2.ed. Rio de Janeiro: Zahar, 1979.

LALANDE, André. Vocabulário técnico e crítico da filosofia. São Paulo: Martins Fontes, 1999.

LEGRAND, Gerard. Dicionário de Filosofia. Lisboa: Edições 70, 1991.

LÉVY, Pierre. A inteligência coletiva. São Paulo: Loyola, 1998.

LYONS, John. Semântica. Lisboa: Presença/Martins Fontes, 1980. (v.1)

MONTEIRO, Silvana Drumond. A organização virtual do conhecimento no ciberespaço. DataGramaZero - Revista de Ciência da Informação, v.4, n.6, dez. 2003. Disponível em: <http://dgz.org.br/dez03/F_I_art.htm>. Acesso em: 13 de jul. de 2011.

MONTEIRO, Silvana Drumond. O Ciberespaço: o termo, a definição e o conceito. DataGramaZero - Revista de Ciência da Informação, v.8, n.3, Jun. 2007. Disponível em: <http://dgz.org.br/jun07/F_I_art.htm>. Acesso em 13/07/2011.

PIEDADE, Maria Antonieta Requião. Introdução à teoria da classificação. 2. ed. Rio de Janeiro: Interciência, 1983.

POZZI, M. The concept of 'concept' in terminology: a need for a new approach. In: Proceedings of International Conference on Terminology and Knowledge Engineering TKE'99, 5, 1999, Innsbruck. Viena: TermNet, 1999. p. 28-42.

RICKEN, Friedo. (Org.). Dicionário de teoria do conhecimento e metafísica. São Leopoldo: Editora Unisinos, 2003. 
SOARES, Maria Luísa Couto. Conceito e sentido em Frege. Porto: Campo das Letras, 2001.

TRASK, R. L. Dicionário de linguagem e linguística. São Paulo: Contexto, 2004.

VICKERY, Brian C. Classificação e indexação nas ciências. Rio de Janeiro: BNG/Brasilat, 1980.

\section{Title}

Concepts, Categories and Knowledge Organization

\section{Abstract}

Nowadays, the status of knowledge faces epistemological challenges, due to the emergence of new interdisciplinary combinations. In this context, the spread and social appropriation of information take on new forms, requiring different ways to organize information and knowledge. In order to face these challenges, several paradigms about the relationship between knowledge, concepts, category and its operation in documentary languages coexist in the filed of Information and Knowledge Organization. The traditional and canonical principles of concepts organization and the new concept theories, which reveal these paradigms, are presented as a result of an exploratory research. It is emphasized in the conclusion that further research is necessary concerning the existing paradigms as well as a comparison among them to propose new approaches to organize information.

\section{Keywords}

Concepts. Information organization. Knowledge organization. Concept theories.

\section{Título}

Conceptos, categorías y organización del conocimiento

\section{Resumen}

En la época contemporánea, el estatuto del conocimiento enfrenta retos debido a la aparición continua de nuevas combinaciones interdisciplinarias. En este contexto, la apropiación social de la información toma nuevas formas que requieren maneras diferentes de organizar la información y el conocimiento. Para enfrentar estos retos, coexisten en el área de Organización de la Información y del Conocimiento varios paradigmas respecto a la relación entre conocimiento, concepto y su operatividad en lenguajes documentales. Los principios tradicionales de organización de conceptos y las nuevas teorías, reveladoras de dichos paradigmas, se presentan como resultado de una investigación exploratoria. En las conclusiones se destaca la necesidad de profundizar y comparar estos paradigmas de manera a elaborar nuevos enfoques y propuestas para organizar información.

\section{Palabras clave}

Conceptos. Organización de la información. Organización del conocimiento. Teorias del concepto.

Recebido em: 04/09/2011

Aceito em: 07/12/2011 